PISSN 2508-1640 EISSN 2508-1667 an open access journal

East Asian Economic Review vol. 22, no. 1 (March 2018) 3-28

http://dx.doi.org/10.11644/KIEP.EAER.2018.22.1.336

\title{
Harmonization of Rules of Origin: An Agenda for Plurilateral Cooperation?*
}

\author{
Bernard Hoekman ${ }^{\dagger}$ \\ Robert Schuman Centre, European University Institute \\ Bernard.Hoekman@EUI.eu \\ Stefano Inama ${ }^{\dagger \dagger}$ \\ UNCTAD \\ Stefano.Inama@unctad.org
}

\begin{abstract}
This article discusses the deadlock in the WTO on multilateral harmonization of nonpreferential rules of origin (RoO) and reviews some of the RoO included in recent preferential trade agreements. We argue that there is a trend towards adoption of similar approaches and that this suggests that cooperation to reduce the trade-impeding effects of differences in $\mathrm{RoO}$ across jurisdictions is more feasible than often is assumed by observers and policymakers. From a trade facilitation perspective such cooperation could be based on plurilateral initiatives under the umbrella of the WTO. These could include a focus on pursuit of greater convergence between preferential and nonpreferential $\mathrm{RoO}$ helping to achieve the long-standing goal of moving towards harmonization of rules of origin.

Keywords: Rules of Origin, WTO, Trade Agreements, Plurilateral Cooperation, Regulation JEL Classification: F13, F15, F53
\end{abstract}

\section{INTRODUCTION}

Trade agreements require the parties to agree on the rules (regulations) that will determine whether a product is eligible to benefit from whatever provisions are

\footnotetext{
* The views expressed are those of the authors and do not necessarily reflect those of the United Nations. We are grateful to 3 referees for helpful comments and suggestions.

${ }^{\dagger}$ Professor, Robert Schuman Centre for Advanced Studies, European University Institute and Centre for Economic Policy Research, London.

$\because$ Chief, Technical Assistance and Enhanced Integrated Framework section, UNCTAD.
} 
embodied in the agreement. Thus, to be eligible for preferential market access benefits an exporter must document that a good has been produced in an eligible country. Such preferential rules of origin ( $\mathrm{RoO})$ have been the focus of much research, lobbying and policy debate. ${ }^{1}$ To a significant extent the more difficult it is for exporters to satisfy $\mathrm{RoO}$ - the more restrictive or stringent the $\mathrm{RoO}$ are - the less valuable preferential access will be. Less well-known and studied are non-preferential RoO. These are needed to determine whether a product is subject to a nation's trade policy. For example, if the EU imposes an antidumping measure on imports of a product originating in China, there is need to determine the origin of that product to avoid possible circumvention. ${ }^{2}$ The same is true when it comes to access to government procurement markets: if India opens up access to public procurement contracts to firms from China, it will be necessary to determine whether goods are eligible i.e., what constitutes a Chinese product. More generally, all countries regulate what constitutes the origin of a product (so-called marks of origin or country of origin labelling) for consumer information reasons, to be able to implement health and safety-related regulations, for statistical purposes, and so forth.

RoO are distinct from other regulatory policies such as product standards in that compliance is not a necessary condition for being able to export (sell) a product. In the case of preferential trade arrangements, a $\mathrm{RoO}$ is equivalent to a conditional tax: if the RoO is not satisfied an importer must pay the relevant MFN tariff. In the case of a product subject to other types of trade policy - e.g., if there are antidumping duty measures in place - a determination of origin is required to establish whether the antidumping duty applies. In all these cases the RoO does not act to prohibit or prevent a product from entering the market, as can be case for other types of policy - for example, if mandatory health and safety-related product standards are not satisfied. That said, different types of RoO and the specific criteria that apply will

${ }^{1}$ See e.g., Anliker (2016), Soprano (2016), Cadot et al. (2006) or Conconi et al. (2016).

${ }^{2}$ In practice the link with trade defence mechanisms like antidumping is addressed in major jurisdictions such as the US and EU through special anti-circumvention measures. See Inama, Vermulst and Eeckhout (2009). 
have a differential impact on the cost of production and thus the probability that an exporter will choose (or be forced) to pay the applicable MFN tariff.

The most commonly used approaches to determine the origin of products are based on whether a manufacturing or other processing operation results in: (i) an ad valorem percentage calculated according to different approaches; ${ }^{3}$ (ii) a change in tariff heading, i.e., how a product is classified in the Harmonized Commodity Description and Coding System (the Harmonized System or HS), the tariff classification nomenclature used by WTO members; or (iii) involves the use of a specific technology, method or process. A recent trend is the adoption of an upper bound on the amount or share of imported (non-originating) physical materials that may be embodied in a product. The latter is easier for firms to understand and to comply with than value added based criteria, and has been advocated by low-income countries in the context of non-reciprocal preferential market access programs implemented by OECD nations and emerging economies (Inama, 2011).

Differences in specific $\mathrm{RoO}$ across products that are applied by importing countries increase the complexity of trade policy for businesses, generate trade costs and may affect investment and sourcing decisions in ways that reduce efficiency. Moreover, differences between countries in the RoO for the same product further increases complexity for traders that sell to multiple markets. Differences across RoO regimes maintained by importing countries create costs for firms as they imply that firms seeking to benefit from preferential access regimes must ensure that their production processes are tailored so as to satisfy the RoO regime prevailing in each market they sell to. Such additional cost effects also arise in the case for non-preferential RoO: differences across countries, both in terms of substantive requirements and in terms of labelling, will imply specific fixed costs of exporting to different markets. Thus, $\mathrm{RoO}$ may act as nontariff barriers for any given market, and differences in $\mathrm{RoO}$ across markets can have analogous effects to differences in the regulatory requirements that apply to a product in different countries. Reducing such heterogeneity is a potential way to reduce the costs associated with RoO. As discussed below, this

3 Such approaches may be summarized as (i) whether a minimum share of the value added embodied in a product was the result of activities in the last country in which the product was processed according to different calculation techniques or (ii) a given percentage of non-originating materials has not been exceeded or a minimum percentage of originating inputs has been used in the manufacturing of the finished product. 
has long been on the multilateral trade policy agenda, but only for non-preferential $\mathrm{RoO}$. The reason is that preferential $\mathrm{RoO}$ are argued to fall outside the ambit of the WTO because (i) non-reciprocal trade preferences are granted at the discretion of importing countries; and (ii) in the case of discriminatory preferential trade agreements (PTAs) there is a tacit consensus that WTO members should be free to define their own $\mathrm{RoO}$ to determine if a product is eligible for the tariff preference - i.e., there is acceptance of policy space for this dimension of the implementation of PTAs. ${ }^{4}$

Economic research on $\mathrm{RoO}$ has largely focused on estimating their trade-distorting effects, often using methodologies that are centred on estimating the ad valorem tariff equivalents of $\mathrm{RoO}^{5}$ or classifying $\mathrm{RoO}$ into types and constructing indexes in order to assess the relative restrictiveness of $\mathrm{RoO}$ across countries and trade agreements. ${ }^{6}$ While such efforts are important in determining how RoO can (and do) act as nontariff barriers to trade, this type of research is not particularly useful in informing efforts by governments seeking to cooperate on RoO to facilitate trade. Such efforts require detailed analysis of the specific RoO adopted by different countries or trade blocs, their evolution over time, and an understanding of where governments have adopted rules that are similar or equivalent.

In what follows we first briefly review in Section 1 the state of play in the WTO with respect to efforts to harmonize nonpreferential RoO. Section 2 discusses developments regarding RoO in recent PTAs. Section 3 presents some preliminary evidence regarding the extent of regulatory heterogeneity in the area of preferential RoO. This suggests that many of the preferential RoO adopted in recent PTAs are not very dissimilar from the draft harmonized non-preferential RoO that emerged from WTO deliberations. While significant differences in RoO remain across products and countries, there appears to be a trend towards greater convergence. Section 4 makes some proposals for moving forward in reducing the costs of regulatory heterogeneity in this policy area on a plurilateral basis, given a presumption that the prospects for full harmonization of either nonpreferential or preferential RoO will remain limited. Section 5 concludes.

${ }^{4}$ See, e.g., Keizer (1997) and Inama (2009).

5 See, e.g., Cadot and Ing (2016), Cadot, Carrere, de Melo and Tumurchudur (2006) and Conconi et al. (2016).

${ }^{6}$ Estevadeordal et al. (2009). 


\section{WTO RULES AND NEGOTIATIONS ON HARMONIZATION OF NONPREFERENTIAL RoO}

The GATT left importing nations free to define what criteria or conditions they apply to determine the origin of a product as long as these are applied on a mostfavoured-nation basis. The same applies to preferential access programs for developing countries: these may not discriminate across eligible developing exporting countries. ${ }^{7}$ However, there have been efforts over time to establish greater multilateral discipline on RoO. These culminated in the Uruguay round Agreement on Rules of Origin (ARO), one of the multilateral agreements that is overseen by the WTO. The ARO requires that non-preferential $\mathrm{RoO}$ be applied in non-discriminatory manner, are transparent, are not designed to be a barrier to trade, and are administered in a consistent, uniform, impartial, and reasonable manner. It does not impose substantive obligations on the content or design of RoO. The ARO set the ambitious objective of the adoption of a single set of nonpreferential rules of origin "equally for all purposes" to avoid a situation where RoO may vary across products and may even vary for a given product depending on the type of trade policy instrument they apply to. In practice, a country may use more restrictive $\mathrm{RoO}$ for antidumping actions than it does, for example, to trade in the same product(s) that occurs under the umbrella of a mutual recognition agreement pertaining to applicable technical standards.

7 Mavroidis (2016). RoO are an important dimension of free trade agreements, but the GATT/WTO does not impose any rules on the RoO that signatories of such agreements apply notwithstanding the general recognition that such $\mathrm{RoO}$ are not just a matter of concern to participating countries but can affect third parties. For example, in the context of the 1972 FTA between the EEC and EFTA States, the US argued that the rules of origin would generate ' ...trade diversion by raising barriers to third countries' exports of intermediate manufactured products and raw materials. This resulted from unnecessarily high requirements for value originating within the area. In certain cases the rules disqualify goods with value originating within the area as high as 96 percent. The rules of origin limited non-originating components to just five percent of the value of a finished product of the same tariff heading [for] nearly one-fifth of all industrial tariff headings. In many other cases a 20 percent rule applied' (GATT, 1974:152-153 cited in Hoekman and Kostecki, 2009).

${ }^{8}$ See Article 9 (1) (a) of the Agreement on Rules of Origin (ARO). 
In addition to the goal of using the same RoO for all purposes, the most important objective of the ARO is to work towards the harmonization of non-preferential RoO (Art. 9) across countries. This has been pursued through a Harmonization Work Programme (HWP) managed by the WTO Committee on Rules of Origin, and primarily executed by a Technical Committee that involves the active participation of the World Customs Organization (WCO). The ARO provides for the development a set of nonpreferential harmonized RoO based on the change of tariff classification (using the Harmonized System) as the preferred method to define substantial transformation. ${ }^{9}$ In cases where the HS nomenclature does not allow substantial transformation to be determined by a change in tariff classification test, the Technical Committee was to consider the use of supplementary tests such as value added criteria or agree on 'specific manufacturing processes' that if used confer origin (i.e., imply sufficient transformation of a product has occurred).

The HWP was supposed to be completed in July 1998. Results of the technical review undertaken by the WCO were submitted to the WTO by a revised deadline of November 1999. As of today, however, the HWP and the associated draft text has yet to be completed by the WTO Committee on Rules of Origin (CRO). Despite considerable progress, as witnessed by the development of a draft text, a final consensus could not be obtained. This reflects opposition of some WTO members, notably the United States, to the implications of the results of the HWP for different WTO agreements. The main reason for concern by these countries is that adoption of harmonized nonpreferential RoO across would affect (constrain) the discretion of government agencies in implementing specific trade policies - such as antidumping measures. This so-called "implications issue" led to the cessation of formal negotiations in the mid-2000s. ${ }^{10}$

Discussions in the WTO since 2007 have been limited to updating the draft HWP text on Harmonized Rules of Origin to reflect new versions of the Harmonized

9 See ARO, Article 9 (1) (c) ii.

10 Since then another "implication" of harmonization has been highlighted by China, which has been a proponent of harmonization of non-preferential $\mathrm{RoO}$ as a means of improving the measurement of trade balances by better accounting where value is added in the production of goods (i.e., to reflect the fact that many of the goods that are counted as Chinese in the import statistics of trading partners are not of Chinese origin since most of the value embodied in them is associated with inputs originating in third countries).

(c) Korea Institute for International Economic Policy 
System and informal workshops on the consequences of the absence of harmonised RoO for business. In 2016 Switzerland initiated informal consultations among WTO members on a limited negotiating agenda aiming at making progress by focusing on areas where pragmatic approaches could be taken to facilitate trade in the absence of full harmonization of non-preferential RoO. This initiative was inspired by the successful format of the Nairobi Ministerial Decision on preferential rules of origin for LDCs. The Swiss proposals centred on two specific dimensions: "transparency" and "certification" (Delegation of Switzerland, 2016). The former has to do with the fact that most notifications made to the WTO are either out of date and/or incomplete. A proposed initiative on the latter seeks to reduce or remove the need for certificates of nonpreferential origin, which are argued to constitute redundant red tape and a needless cost to business. We return to the potential for greater pursuit of such pragmatic approaches in Section 5.

In the case of preferential RoO there have been a number of developments since the late 1990s. One concerns implementation of unilateral preferential programs. Starting in 2005, developed countries committed to facilitate exports of the leastdeveloped countries (LDCs) by providing these nations with duty-free, quota-free (DFQF) access for at least 97 percent of product lines. A number of OECD countries, including the EU, have implemented programs that provide $\mathrm{DFQF}$ access to all products except arms. This gave rise to discussion in the WTO on RoO, with the LDCs arguing that strict RoO substantially reduced the value of DFQF access. As a result there have been deliberations and some progress in agreeing to adopt RoO that are simpler and easier to satisfy. The pursuit of incremental convergence in the RoO that apply for LDCs has complemented the long-running effort to agree to harmonize $\mathrm{RoO}$ for non-preferential trade policy purposes.

\section{RoO IN RECENT PTAs}

Despite the stalemate on non-preferential RoO, negotiations on preferential RoO have thrived as a result of negotiation of new PTAs and efforts by developing countries to enhance the economic salience of non-reciprocal preferential market access programs. A basic tenet (the conventional wisdom) of most RoO experts and trade officials is that there are no possible spillovers among preferential and non-preferential 
RoO, since they serve different trade policy objectives. Preferential RoO serve to determine whether a preferential tariff is applicable under a RTA or a unilateral arrangement, while non-preferential RoO serve to determine the application of mostfavoured nation (MFN) trade policies and specific WTO agreements.

Recent research on private industry experience and views on dealing with RoO reveals that this distinction is not very important for firms. For many firms compliance with rules of origin is a normal part of a business transaction that has a cost. The main difference between preferential and non-preferential RoO is that the former are associated with an expected benefit of reduced duty or duty free entry in the export market, but in many cases companies are obliged to comply with RoO in any event. A recent survey (Anliker, 2016) revealed a 100 percent awareness by respondent companies of non-preferential RoO, with some 55 percent of firms perceiving non-preferential rules to be relevant to their daily operations. Reasons for this included such RoO being demanded by clients, by importing country Customs authorities and/or financial service providers (e.g., for letters of credit). This helps to explain why large companies are prepared to incur the cost of buying and maintaining sophisticated IT systems and related personnel to be able to more efficiently assure compliance with RoO - both preferential and non-preferential (Soprano, 2016). Smaller companies are generally less aware and less able to assess the importance of $\mathrm{RoO}$ in their day to day business. Most companies favour harmonizing RoO as a measure to facilitate trade and bring down cost of compliance, with a clear preference for greater acceptance and use of self-declaration of origin by firms as opposed to having to use certificates of origin issued by certifying authorities or Chambers of Commerce (the latter generally give rise to fees associated with obtaining such certification).

There has been considerable evolution in the technique and content of drafting RoO in PTAs. South-South agreements - e.g., the Southern African Development Community (SADC); the Common Market for Eastern and Southern Africa (COMESA); Southern Common Market (MERCOSUR) and the Association of Southeast Asian Nations (ASEAN) - traditionally adopted a simple formula, such as an across-theboard percentage criterion mirroring the percentage rules in the US Generalized System of Preferences (GSP) scheme (Inama, 2011). In addition they often adopted as an alternative a change of tariff heading criterion following the EU model. In short, these PTAs have not developed their own RoO model. Over time they developed product specific rules of origin (PSRO), but again borrowing the drafting techniques 
from the existing US and EU models. This is the case for Asian trading nations Japan, South Korea, the ASEAN countries - as well, which have borrowed heavily from the North American model for RoO (Inama and Sim, 2015).

In practice the method for calculating the ad valorem percentage criterion in most Asian PTAs is very similar to the method adopted in the PTAs that were concluded by the US subsequent to adoption of the North American Free Trade Agreement (NAFTA). Asian countries have also largely adopted the change of tariff classification criterion as the preferred method for defining product-specific rules of origin in their PTAs, in a similar vein to the NAFTA model. ASEAN countries for a long time pursued a policy to determine their own version of the ad valorem percentage criterion and defining product-specific $\mathrm{RoO}$. This changed following the negotiation of PTAs with Australia and New Zealand, which had adopted the North American model in their PTAs with US. The latest iteration of ASEAN rules of origin in the ASEAN Trade in Goods Agreement (ATIGA) demonstrates the domino effect of the North American model: the calculation of ad valorem percentage criteria is similar to the NAFTA model and the product-specific RoO are based on a default change in tariff classification as an alternative to the traditional $40 \%$ ad valorem percentage. The earlier ASEAN rules of origin were the basis of agreement in the initial PTAs between ASEAN and China in the mid-2000s, but more recent PTAs such as the China -South Korea agreement have adopted RoO that are inspired by the North American model. In short, Asian countries mostly have tended to follow the basic NAFTA approach towards RoO. This "revealed preference" was also illustrated in the final text of 2016 Trans-Pacific Partnership (TPP), with a set of RoO that largely draw on the North American model. ${ }^{11}$

Despite the often claimed rigid separation between non-preferential and preferential $\mathrm{RoO}$, the border between the two regimes has always been porous. NAFTA had a major influence on the WTO ARO. It was US insistence that resulted in the change of tariff classification (CTC) becoming the preferred methodology for drafting rules for non-preferential $\mathrm{RoO}$ - as opposed to the EU approach of using a combination of

11 Although the US ended up withdrawing from the TPP, Canada and Mexico are also signatories to the TPP and are members of the subsequent effort by the remaining 11 signatory countries to implement most of what was agreed under the umbrella of the Comprehensive and Progressive Agreement on Trans-Pacific Partnership (CPTPP). In this paper we focus on the ROO included in the original TPP. 
criteria - the CTC, percentage criterion and specific working and processing requirements. By itself this could be interpreted as a first sign of convergence, even though there are different modalities across PTAs in drafting RoO according to the CTC criterion. This primacy of the CTC over other methodologies for determining substantial transformation gave rise to discussions during the initial phases of the HWP negotiations between the EU and NAFTA partners in the Technical Committee on Rules of Origin (TCRO) and later in the WTO CRO. The 1996-99 TCRO negotiation on non-preferential $\mathrm{RoO}$ was the first time the EU and the US confronted each other on this matter. Before that time the EU had for some 20-plus years been dealing with RoO in the context of its PTAs with European Free Trade Association (EFTA) members and the African, Caribbean, and Pacific (ACP) countries. All these countries were confronted with the then newly matured experience of the US and its partners obtained in negotiating the Canada-US Trade Agreement (CUSTA) and the NAFTA.

While negotiators in the TCRO argued that preferential RoO did not have a bearing on the HWP discussions, it was clear, as demonstrated by the dynamics of the negotiations, that the discussions on non-preferential RoO started from their respective national/regional preferential $\mathrm{RoO}$ backgrounds and experience, at least at the technical level. In other words, each "bloc" proposed and defended its own model of RoO. The eventual draft text that emerged from the HWP largely reflected a compromise between the EU and NAFTA models, with a number of innovations and some disagreement on specific sectors, like machinery. ${ }^{12}$ In retrospect, the 1999 draft harmonized rules of origin (HRO) text represents a tangible sign of convergence that, even if not adopted, influenced the way $\mathrm{RoO}$ were negotiated in subsequent PTAs. An example is the progressive acceptance of the use of the wholly obtained criterion as a requirement for the list of product-specific rules (a typical EU feature) included in the EU-Mexico agreement and later in the Canada-EU Comprehensive Economic and Trade Agreement (CETA). Another example is the use of chemical reactions, a concept inherited from the HWP work, as a specific requirement for some chemical products given the inherent technical difficulty of determining the

12 The "machinery package" allowed each member to choose either a "change of tariff classification rule" (the preferred US method for origin determination) or a "value-added rule" (the preferred EU method for determining origin in this specific sector and circumstance. ${ }^{12}$ This is the so-called dualrule approach. See WTO document JOB(07)/73). 
corresponding CTC for chemical products. Some of these areas of convergence were later reflected in the $\mathrm{RoO}$ included in trade agreements that Asian countries negotiated with the EU and US, and, more recently, the RoO that apply in trade agreements negotiated among Asian countries.

Despite the HWP coming to a standstill in 2007, the many PTAs that have been negotiated since then have implied that $\mathrm{RoO}$ are front and centre in the negotiating agenda of the majority of WTO members. The EU in particular made substantial changes to its RoO model starting in the early 2000s. First, it progressively abandoned the "straight jacket" model that it imposed on itself as a result of its Pan-European RoO that were adopted in the early 1990s. According to the Pan European RoO model each EU PTA partner had to adopt an almost identical set of rules of origin set by the EU including the PSROs to allow cumulation among different PTAs and avoid a proliferation of divergent RoO across PTAs (Bombarda and Gamberoni, 2013). While strictly adhered to for more than a decade, this approach was revealed to be excessively rigid when EU was negotiating with large trading partners because it did not allow concessions to be made on PSROs. Second, the EU undertook a sweeping and unprecedented reform of unilateral RoO, especially for the LDCs. While limited to developing countries, this reform provides a potential base on which to build in further reforms of EU RoO.

The developments in preferential RoO in PTAs have led to some simplification and streamlining of the RoO, informed by lessons learned over more 20 years of operation of major PTAs. Progressively, the EU and the US, as well as counterpart OECD nations (e.g., Japan, South Korea, Australia, and New Zealand) have abandoned methodologies based on calculations of value added in favour of a value of materials used ad valorem percentage calculation. Some innovations have also been introduced, such as the deduction of cost of freight and insurance in recent US PTAs and in the TPP. There are, of course, differences in the arithmetical calculations and definitions of what goes into the numerator and denominator, but there is convergence towards determining ad valorem percentages based on a value of materials calculation rather than a value added or net cost approach, as used in NAFTA for automotive products. This tendency is confirmed by the evolution of the use of the net cost method in US PTAs that has been gradually introduced in subsequent agreements, and the introduction of the build-up and build-down method that has replaced the transaction value used in NAFTA - see Table 1. 
Table 1. Evolution of the NAFTA Percentage-calculation Based RoO

\begin{tabular}{lccccccc}
\hline $\begin{array}{l}\text { Regional value } \\
\text { content criterion }\end{array}$ & NAFTA & CHL-USA & CAFTA & US-SIN & US-AUS & US-KOR & TPP \\
\hline $\begin{array}{l}\text { No. of PSRO } \\
\text { of which: }\end{array}$ & 1,125 & 1,043 & 1,017 & 2,974 & 965 & 758 & 1,245 \\
$\quad$ Net cost & 323 & 0 & 6 & 0 & 0 & 6 & 22 \\
Transaction & 248 & 0 & 0 & 0 & 0 & 0 & 0 \\
Build-up & 0 & 164 & 146 & 239 & 148 & 147 & 398 \\
Build-down & 0 & 157 & 147 & 213 & 144 & 152 & 457 \\
\hline
\end{tabular}

Source: Own calculations.

Note: PRSO: product-specific RoO.

Thus, developments regarding preferential $\mathrm{RoO}$ in the PTAs that include the major players are pointing towards simplification and streamlining. This has supported greater trade as shown by the relatively high utilisation rate of major PTAs, which range from 80 percent to 90 percent (Swedish Board of Trade and UNCTAD, 2017). In a nutshell, there has been a lot of work on RoO that has had a pay-off. This complements reforms of RoO that apply to unilateral tariff preferences offered to LDCs. Such reforms were implemented by Canada in 2003 and by the EU for its "Everything But Arms" (EBA) duty-free, quota-free access program for LDCs, with the EBA rules of origin most recently redefined in 2011. More recently Japan also took the initiative to liberalize the RoO for LDCs for knitted and crocheted garments of HS chapter 61. These initiatives have contributed to the debate over simplification and relaxation of preferential $\mathrm{RoO}$, brought new life to the discussions in the CRO and helped underpin two WTO Ministerial Decisions on preferential $\mathrm{RoO}$ for LDCs, illustrating that progress can be made at the multilateral level. The challenge now is to build on this progress to resume work at the multilateral level on non-preferential RoO.

\section{ASSESSING DIFFERENCES IN RoO: A CONVERGENCE TREND?}

The lack of progress and meaningful discussions on $\mathrm{RoO}$ at the multilateral level since 2007 contrasts with the gradual movement towards de facto and de jure convergence across both preferential and non-preferential RoO in major jurisdictions. 
Divergence certainly continues to exist for some sectors, but it is important to recognize that the situation "on the ground" has been changing. This suggests that multilateral discussions can build on this and focus on the reasons for continued divergence in specific sectors. In pursuing reforms and to better understand RoO regimes it is necessary to distinguish between the policy-objectives that underpin a given set of RoO (the "substance") from the specific criteria used and how they are administered, i.e., the "format" of a RoO. The substantive dimension of a RoO is the degree of restrictiveness related to the value chain it impacts on. It is the substance that matters. If countries have common objectives as to what $\mathrm{RoO}$ are supposed to do, it is much more straightforward to achieve convergence, since the form a RoO takes is mostly a matter of drafting methodology.

Although blocked for almost a decade at the time of writing, the mandate of the CRO to pursue harmonization of RoO provides a continuing opportunity to revitalize multilateral discussion on RoO at the WTO by drawing on and building on PTA experiences as well as unilateral reforms. Making progress in the $\mathrm{CRO}-$ or for that matter in developing the RoO associated with new PTAs - can be facilitated by a better understanding of how different $\mathrm{RoO}$ have evolved and the extent to which they are different. A challenge in assessing this is to compare different RoO for a given product. Such comparisons need to be undertaken at the 6-digit level of the HS classification (i.e., the subheading level). This spans over 6,000 categories. Ideally, one would concord different sets of $\mathrm{RoO}$ to each other at the product level and automate the codification of PRSO using algorithms to classify different RoO into "types." This is a major challenge given the variations in formats and textual language used to define PRSO in different PTAs and non-reciprocal preferential trade arrangements.

Economic analysis has sought to classify RoO by type and assess their relative restrictiveness on an ex ante basis using a mix of judgment and econometric estimation. Estevadeordal (1999) pioneered such analysis, focusing on NAFTA RoO. ${ }^{13}$ In this type of approach, each rule or set of rules is codified depending on the type of criterion used to define $\mathrm{RoO}$ at the product level and a qualitatively ordered index is constructed based on a set of assumptions regarding the relative restrictiveness of alternative types of $\mathrm{RoO}-$ e.g., changes of tariff classification at different HS

13 See also Estevadeordal and Suominen (2006; 2008). 
levels of disaggregation. While a useful approach to quantify the potential effects of different RoO, it is not very helpful if the goal is assess the degree of similarity of different $\mathrm{RoO}$ for a given product. The key challenge here is to characterize and "map" different approaches and requirements into common and comparable categories at a useful level of disaggregation. If the classification is designed at too broad a level, limiting the coding to the main principles used to define origin, there is little value added since this will result in different sets of RoO being compared or lumped together on the basis of oversimplified assumptions that do not reflect the complexity and diversity of RoO. On the other hand, if the taxonomy is designed in a very detailed manner, the task of codification becomes very difficult to operationalize in a way that is useful.

In practice any effort to characterize the similarity of different criteria and approaches to determine origin must include some element of expertise and thus subjective judgement. Crivelli and Inama (2017) undertake a detailed comparison between the HRO and a selection of recent PTAs. They do this at the HS subheading level (there are 6366 sub-headings in the HS classification), focusing on the applicable PSRO with the aim of identifying instances of convergence, partial convergence or divergence among: (i) the results of the HWP process as last updated (the draft HRO); (ii) the TPP and the US-Korea agreement as examples of the NAFTA model of RoO that are mainly based on CTC and regional value content criteria; and (iii) the CETA - the first instance of the European and North American models coming to confront each other - and the EU-South Korea trade agreement. In order to draw such a comparison a taxonomy is developed to compare each of the PSRO contained in the abovementioned PTAs, using the following categories: (a) totally or partially convergent; and (b) divergent. The first category is subdivided into three groups: (i) all rules of origin (the four PTAs and the HWP) are identical or similar in terms of stringency and drafting form; (ii) the majority of the $\mathrm{RoO}$ are identical or similar in terms of stringency and drafting form; and (iii) the $\mathrm{RoO}$ are identical or similar in terms of stringency but have a different drafting form. Divergence occurs if there is a difference in terms of stringency and drafting form, distinguishing between instances where the $\mathrm{RoO}$ are either more or less stringent than the equivalent HRO provisions. 
Table 2. Comparison of 6-digit PRSO: HWP, CETA, US-Korea, EU Korea, and TPP

\begin{tabular}{cccccc}
\hline $\begin{array}{c}\text { Convergence/ } \\
\text { Divergence } \\
\text { categories }\end{array}$ & Category description & $\begin{array}{c}\text { No. of } \\
\text { tariff } \\
\text { lines }\end{array}$ & Share & $\begin{array}{c}\text { Average } \\
\text { MFN }\end{array}$ & $\begin{array}{c}\text { Total QUAD imports } \\
\text { from the world } \\
\text { (US\$ million) }\end{array}$ \\
\hline 1 & Totally convergent & 135 & $2 \%$ & 1,52 & 641,546 \\
\hline 2 & Partially convergent & 1 '287 & $20 \%$ & 2,76 & 2298,623 \\
\hline 3 & $\begin{array}{c}\text { Partially convergent in stringency; } \\
\text { different form of drafting }\end{array}$ & 1 '994 & $31 \%$ & 3,15 & 1648,448 \\
\hline 4 & $\begin{array}{c}\text { Divergent, more stringent compared } \\
\text { with HRO (HWP) draft rules }\end{array}$ & 823 & $13 \%$ & 5,49 & 960,754 \\
\hline 5 & $\begin{array}{c}\text { Divergent, but less stringent than } \\
\text { HRO (HWP) draft rules }\end{array}$ & $2 ‘ 127$ & $33 \%$ & 6,00 & $1,321,871$ \\
\hline Total & & $6 ‘ 366$ & $100 \%$ & & \\
\hline
\end{tabular}

Source: Crivelli and Inama (2017).

Crivelli and Inama (2017) show that governments have been able to make progress at product specific level in adopting RoO that are similar. Their comparisons of the draft HRO that came out of the WTO Harmonization Work Programme (HWP) for non-preferential origin rules with the RoO in these recent PTAs suggests there has been progress in simplification and convergence at sectoral level, despite the unwillingness of some governments to embrace the full HRO package. They find there is evidence of movement towards convergence and simplification of RoO: $53 \%$ of all tariff lines at six digit level show a degree of convergence (Table 2). If tariff lines where the PRSO in the covered PTAs differ from the HRO but are more liberal are added to this (33\% of the total), some $85 \%$ of the PSRO taken together are ether convergent and/or liberal. These are preliminary results that need to be further refined and validated. Moreover, it should be recognized that this type of analysis is partial as the focus is only on PRSO and ignores other dimensions of RoO regimes such as cumulation or the level of de minimis thresholds. That said, their findings reveal that:

- There are sectors where there is significant convergence for some product categories - e.g., chemicals (helping to explain why this was one of the sectors where there was an early harvest in the TTIP negotiations); 
- Differences often relate more to "form" than substance - i.e. the way in which the RoO are drafted frequently differ across PTAs but this need not imply major differences in the degree of stringency of the RoO; and

- For some sensitive sectors, e.g., clothing and fisheries, there is substantial divergence in $\mathrm{RoO}$.

The extent to which the PRSO are convergent/divergent is illustrated further in Tables 3 and 4. These tables provide examples of cases of convergence for some sectors, as well as continued areas of divergence. Since Asian countries have largely adopted the North American model in setting their product specific rules of origin the results of this research may be particularly relevant since the starting point shows already a certain degree of convergence on the adoption of a model based on similar calculation of ad valorem percentage and use of change of tariff classification criteria.

The boldface text in Table 3 shows where there is significant convergence or equivalence among the agreements. To some extent recent progress towards convergence between preferential and non-preferential $\mathrm{RoO}$ and more generally simplification of RoO has been facilitated by the removal of MFN tariffs for products - e.g., because of the Information Technology Agreement (ITA) and analogous zero-forzero sectoral agreements for chemical products. However, there are also other sectors with positive MFN duties where convergence has been occurring. What is needed now is further research to validate the initial findings and narrow down the results and most of all a political momentum to trigger the change. The results presented here suggest that there is value in seeking to identify emerging "best practices" for sectors where there is convergence and to identify sectors where there is continued divergence. 
Table 3. HRO, CETA, TPP, EU and US PTAs with South Korea: Signs of Convergence Example 1

\begin{tabular}{|c|c|}
\hline HS Code & $\begin{array}{l}28.50 \\
\text { Hydrides, nitrides, azides, silicides and borides, whether or not chemically defined, } \\
\text { other than compounds which are also carbides of heading } 28.49 \text {. }\end{array}$ \\
\hline $\mathrm{HRO}$ & CTH \\
\hline CETA & $\begin{array}{l}\text { A change from any other subheading, or: } \\
\text { A change from within any one of these subheadings, whether or not there is also a } \\
\text { change from any other subheading, provided that the value of non-originating } \\
\text { materials classified in the same subheading as the final product does not exceed } 20 \\
\text { per cent of the transaction value or ex-works price of the product. }\end{array}$ \\
\hline TPP & A change to a good of heading 28.50 from any other heading. \\
\hline EU_KOR & $\begin{array}{l}\text { Manufacture from materials of any heading, except that of the product. } \\
\text { However, materials of the same heading as the product may be used, provided that } \\
\text { their total value does not exceed } 20 \% \text { of the ex-works price of the product }\end{array}$ \\
\hline US-KOR & A change to heading 28.10 through 28.53 from any other heading. \\
\hline
\end{tabular}

Example 2

\begin{tabular}{|c|c|}
\hline HS Code & $\begin{array}{l}87.12 \\
\text { Bicycles and other cycles (including delivery tricycles), not motorized }\end{array}$ \\
\hline HRO & CTH, except from heading 87.14 ; or $35 \%$ value added rule \\
\hline CETA & $\begin{array}{l}\text { A change from any other heading, except from 87.14; or } \\
\text { A change from heading } 87.14 \text {, whether or not there is also a change from any other } \\
\text { heading, provided that the value of non-originating materials of heading } 87.14 \text { does } \\
\text { not exceed } 50 \% \text { of the transaction value or ex- works price of the product }\end{array}$ \\
\hline ТPР & $\begin{array}{l}\text { A change to a good of heading } 87.12 \text { from any other heading, except from } \\
\text { heading 87.14; or } \\
\text { No change in tariff classification required for a good of heading } 87.12 \text {, provided } \\
\text { there is a regional value content of not less than: } \\
\text { a) } 35 \% \text { under the build-up method; or } \\
\text { b) } 45 \% \text { under the build-down method; or } \\
60 \text { per cent under the focused value method taking into account only the non- } \\
\text { originating materials of heading } 87.12 \text { and } 87.14\end{array}$ \\
\hline EU_KOR & $\begin{array}{l}\text { Manufacture in which the value of all the materials used does not exceed } 45 \% \text { of the } \\
\text { ex-works price of the product }\end{array}$ \\
\hline US-KOR & $\begin{array}{l}\text { A change to heading } 87.12 \text { through } 87.13 \text { from any other heading, except from } \\
\text { heading } 87.14 \text {; or, provided that there is a regional value content of not less than: } \\
\text { (a) } 35 \text { percent under the build-up method, or (b) } 45 \text { percent under the build-down method. }\end{array}$ \\
\hline
\end{tabular}


Table 4. HRO, CETA, TPP, EU and US PTAs with South Korea: Signs of Divergence Example 1

\begin{tabular}{l|l}
\hline HS Code & $\begin{array}{l}16.04 \\
\text { Prepared or preserved fish; caviar and caviar substitutes prepared from fish eggs. }\end{array}$ \\
\hline HRO & CTH \\
\hline CETA & A change from any other chapter, except from Chapter 3 \\
\hline TPP & A change to a good of heading 16.05 from any other chapter. \\
\hdashline EU_KOR & $\begin{array}{l}\text { Manufacture: } \\
\text { - for animals of Chapter 1, and/or } \\
\text { - in which all the materia1s of Chapter 3 used are wholly obtained }\end{array}$ \\
\hline US-KOR & A change to heading 16.05 from any other chapter \\
\hline
\end{tabular}

Example 2

\begin{tabular}{l|l}
\hline HS Code & $\begin{array}{l}6203.42 \\
\text { Men's Cotton Pants }\end{array}$ \\
\hline HRO & $\begin{array}{l}\text { Change to goods of this split chapter provided that the goods are assembled in a } \\
\text { single country in accordance with Chapter Note. }\end{array}$ \\
\hline $\begin{array}{l}\text { Weaving accompanied by making up (including cutting); or } \\
\text { Making up preceded by printing accompanied by at least two preparatory or finishing } \\
\text { operations (such as scouring, bleaching, mercerising, heat setting, raising, calendaring, } \\
\text { shrink resistance processing, permanent finishing, decatising, impregnating, mending } \\
\text { and hurling), provided that the value of the unprinted fabric used does not exceed } 47.5 \\
\text { per cent of the transaction value or ex-works price of the product. }\end{array}$ \\
\hline $\begin{array}{l}\text { A change to a good of heading 62.01 through 62.08 from any other chapter, except } \\
\text { from heading 51.06 through 51.13, } \\
52.04 \text { through 52.12 or } \\
54.01 \text { through 54.02, subheading 5403.33 through 5403.39 or } \\
5403.42 \text { through 5403.49, or } \\
\text { heading 54.04 through 54.08, 55.08 through 55.16, 58.01 through 58.02 or } \\
60.01 \text { through 60.06, provided the good is cut or knit to shape, or both, and sewn or } \\
\text { otherwise assembled in the territory of one or more of the Parties. }\end{array}$ \\
$\begin{array}{l}\text { Weaving accompanied by making-up (including cutting) or } \\
\text { Embroidering accompanied by making up (including cutting), provided that the value of the } \\
\text { unembroidered fabric used does not exceed } 40 \% \text { of the ex-works price of the product or } \\
\text { Coating accompanied by making up (including cutting), provided that the value of the } \\
\text { uncoated fabric used does not exceed } 40 \% \text { of the ex works price of the product or } \\
\text { Making-up preceded by printing accompanied by at least two preparatory finishing } \\
\text { operations (such as scouring, bleaching, mercerising, heat setting, raising, } \\
\text { calendaring, shrink resistance processing, permanent finishing, decatising, } \\
\text { impregnating, mending and hurling), provided that the value of the unprinted fabric } \\
\text { used does not exceed 47.5\% of the ex-works price of the product }\end{array}$ \\
\hline EU_Ko.
\end{tabular}

(c) Korea Institute for International Economic Policy 
Table 4. Continued

Example 2

\begin{tabular}{l|l}
\hline US-KOR & $\begin{array}{l}\text { A change to subheading 6203.41 through 6203.49 from any other 4-20 chapter, except } \\
\text { from heading 51.06 through 51.13, 52.04 through 52.12, 53.07 through 53.08, or } \\
53.10 \text { through 53.11, 54.01 through 54.02, } \\
\text { subheading 5403.33 through 5403.39, 5403.42 through heading 54.08, or } \\
\text { heading 55.08 through 55.16, 58.01 through 58.02, or } \\
\text { 60.01 through 60.06, provided that the good is both cut and sewn or } \\
\text { otherwise assembled in the territory of one or both of the Parties. }\end{array}$ \\
\hline
\end{tabular}

\section{MOVING FORWARD: PLURILATERAL COOPERATION ON RoO UNDER WTO AUSPICES?}

The experience with the HWP makes clear that a top down effort to harmonize nonpreferential $\mathrm{RoO}$ is very difficult, largely because of concerns by some countries that this will constrain their policy space. At the same time, it is important to recognize that at the technical level substantial progress was made on defining a set of harmonized RoO in the HWP. Moreover, "bottom up," à la carte convergence is happening in significant segments of the preferential RoO landscape, as reflected in the RoO that are incorporated into recent PTAs and the progress that has been made in simplification of RoO for LDCs as part of duty-free, quota-free market access programs. This suggests that there is scope for proponents of simplification and harmonization of RoO to leverage the outcome of the HWP and the trend towards convergence of PSROs in PTAs through cooperation between subsets of interested countries.

Cooperation on trade policy matters in the WTO generally has been driven by small-groups of countries with an interest is an issue. In this regard there is a similarity between PTAs - which are by definition initiatives that span only a limited number of countries - and the WTO, the major difference of course being that small group initiatives in the WTO are aimed at multilateral cooperation that spans all WTO members. However, this need not be the case - WTO members may conclude agreements among subsets of countries under the umbrella of the WTO that do not take the form of PTAs. There are two main mechanisms in the WTO for countries to form a "club" on an issue-specific agenda of common interest: conclusion of a Plurilateral Agreement (PA) under Article II.3 WTO, and so-called critical mass agreements (CMAs). CMAs are agreements in which negotiated disciplines apply 
to only a subset of countries, but benefits are extended on a nondiscriminatory (MFN) basis. Examples of CMAs include initiatives such as the Information Technology Agreement (ITA) and other so-called "zero-for-zero" agreements in which a group of countries agree to eliminate tariffs for a specific set of products. CMAs are not limited to goods. They have also been negotiated for specific services sectors. Examples are the Agreement on Basic Telecommunications and the Agreement on Financial Services, both concluded under the auspices of the General Agreement on Trade in Services (GATS) (Hoekman and Kostecki, 2009).

PAs differ from CMAs in that they may be applied on a discriminatory basis that is, benefits need not be extended to non-signatories. There are currently two PAs incorporated into the WTO: the Agreement on Civil Aircraft and the Agreement on Government Procurement. Because PAs may be applied on a discriminatory basis, their incorporation into the WTO requires unanimity - all WTO members must agree that a subset of countries implement a PA. The constraint that PAs be adopted "exclusively by consensus"14 is a major hurdle to overcome, and explains why there are only two PAs, both of which were negotiated during the GATT years, long before the WTO entered into force. The rationale for the consensus rule is that it ensures that nonparticipants cannot be confronted with PAs that may negatively affect them even if they do not join them and, more generally, that all WTO members have a say on the salience and appropriateness of a given policy area being administered by the WTO secretariat (Lawrence, 2006).

Hoekman and Mavroidis (2015a; 2015b; 2017) discuss the modalities of clubbased initiatives in the WTO. There are good reasons for attempting to do more via CMAs and PAs, given the increasing difficulty of concluding multilateral agreements - exemplified by the failure of the Doha Development Agenda to reach a successful conclusion and the current deadlock in the WTO. CMAs and PAs cannot reduce the welfare of any country, including those that decide not to join, because CMAs apply on an MFN basis and PAs must be approved by the WTO Membership as a whole. CMAs and PAs are more transparent than PTAs as they involve formal scheduling of commitments by signatories and regular reporting on activities to the WTO Membership as a whole. They imply less dispersion in rules and approaches - and thus transactions costs and trade diversion - than PTAs. Indeed, they offer a

${ }^{14}$ See Article X.9 of the Agreement Establishing the WTO.

(c) Korea Institute for International Economic Policy 
way to multilateralize elements of what may be covered in PTAs. Multiple PTAs dealing with the same subject matter often do so in ways that imply that the rules of the game for firms differ depending on the PTA that applies for a given trade flow. RoO are one of the most obvious examples of a policy area that can lead to this result.

There is no formal constraint on the ability of a club of WTO Members to pursue CMAs that involve deepening of disciplines on policies that are already subject to WTO rules, as long as they are willing to apply these on an MFN basis (Hoekman and Mavroidis, 2017). Nonpreferential RoO must apply on a MFN basis, suggesting that plurilateral cooperation initiatives in this area will have to take the form of a CMA. What might a plurilateral initiative focus on? Recent submissions to the CRO such as the informal proposals that were made by Switzerland in 2016 on transparency and certification could be the basis of a plurilateral effort for a club of countries to agree to adopt a common set of RoO that are showing convergence. One straightforward way to proceed that is unlikely to confront significant political constraints would be to start with a focus on zero-rated MFN products and agree to implement harmonized nonpreferential RoO for such goods. Given zero MFN rates, it should also be feasible to agree to a single $\mathrm{RoO}$ for such products, i.e., apply the same $\mathrm{RoO}$ to goods from any source, including those originating in PTA partner countries.

Transparency remains a serious problem for firms and other stakeholders - the type of exercise undertaken by Crivelli and Inama (2017) discussed briefly above could be used as a starting point to identify at product-specific level where such convergence has taken place. Such an exercise could be extended to encompass all major PTAs and preferential market access programs under the GSP. A collaborative effort among interested countries to do so will in any event be a necessary condition for identifying where $\mathrm{RoO}$ are already very similar and thus equivalent in terms of underlying regulatory objectives and criteria. Where $\mathrm{RoO}$ are equivalent, there is scope to formally agree to accept ("recognize") the RoO applied by any of the participating members of the club.

CMAs can also be envisaged for cooperation on the administration of RoO, i.e. processes related to the documentary evidence required to demonstrate compliance with $\mathrm{RoO}$ that is often quoted by business as the most exasperating aspect of RoO. This falls under the heading of "certification" and is an area where the multilateral trading system has been conspicously absent. At present Chapter 2 of Annex K of the revised Kyoto Convention 2000 is the only existing multilateral text on administration 
and certification of rules of origin. The administrative dimensions of $\mathrm{RoO}$ mostly apply across all products - there are seldom product-specific administrative requirements. When there are, they mostly apply at broad category levels (an example is textiles and apparel in certain US PTAs). In practice there are only a limited number of ways of administering RoO. The most used methodologies are: (i) certificate of origin on paper issued by certifying authorities with use of stamps and/or signatures; (ii) certificate or statement of origin issued by the exporter (with or without registration with certifying authorities); and (iii) a statement of origin issued by the importer. Overreliance by some customs administrations on out-dated forms of administering $\mathrm{RoO}$ based on documentary evidence - e.g., a certificate of origin, the exchange of seals and signatures of certifying officers, or non-manipulation certificates issued in the country of transit - can make administration of RoO into a non-tariff barrier. Shifting to a Customs-authorised exporter declaration of origin with retroactive checks and post-clearance recovery offers one model for reducing RoO-related administrative costs. The 2017 reform of the EU's RoO for its GSP regime provides for listing registered exporters in a database administered by national customs agencies. Registered exporters will be given a number and may issue a declaration of origin. When this self-declaration is presented at an EU port of entry, customs will consult the joint database to ascertain whether the exporter has been registered and, if so, will grant preferential tariff rates. Verification of an exporter's declaration and post-clearance recovery are part of this administrative method. This is an example of a reform in the administration of RoO that may facilitate trade. There are other options as well, such as the method employed by US Customs and Border Protection, which is based on importer declarations and disregards evidence provided by exporters or certificates of origin issued by third parties. Whatever method is used, reliance on certificates of origin and the exchange of seals and signatures should be a thing of the past. A CMA on certification among a set of countries interested in adopting a common approach to reducing the costs of administering $\mathrm{RoO}$ would reduce the heterogeneity of $\mathrm{RoO}$ regimes confronting international business.

The level of ambition for plurilateral initiatives will depend on the specific interests and objectives of participating countries. For example, single transformation is arguably a good rule of thumb for drafting $\mathrm{RoO}$ in a world characterized by global value chain-based production. Given that this type of production involves firms specializing in specific tasks or activities, RoO that entail a need for more extensive value addition or transformation will undercut the ability of countries to engage in this type of 
production and trade unless they are part of larger regional integration arrangements that permit cumulation for RoO purposes. This is not the case for many developing nations and the design of $\mathrm{RoO}$ therefore should reflect this reality. Traditional protectionist double or triple transformation requirements greatly impede participation in value chains. While it may be difficult to abolish such RoO for "sensitive sectors" - e.g., textiles and clothing for the US, certain processed agricultural products in the EU and Japan - progress on this front has proved possible in the context of implementing DFQF market access programs for LDCs and for many products PTAs have been moving to greater use of single transformation-based $\mathrm{RoO}$ criteria. Sceptics may argue that such a simple rule of thumb is unthinkable but the evidence from recent PTAs and developments in the administration of nonreciprocal preferences schemes suggests that efforts to bring together the relevant actors (firms, Customs and trade officials) can allow reforms to be agreed and implemented. Here again a plurilateral process could form the basis for such deliberations and help to define the potential substance of a CMA.

\section{CONCLUDING REMARKS}

The nature of $\mathrm{RoO}$ - a rather technical and complex subject - is not one that attracts the interest of most trade policy officials and Ministers. Yet these same actors are prone to use $\mathrm{RoO}$ when convenient or expeditious to respond to protectionist lobbies. Business has been ambivalent on the issue of RoO. On the one hand they often complain about the complexity of RoO but on the other hand they do not push Governments to make the extra effort required to seek a multilateral solution. The focus instead has been on "easy fixes" in the context of PTAs, which are seen as more feasible and less costly than focusing on making progress under the WTO umbrella. An emphasis on PTAs may also reflect the evolving nature of international (regional) trade, as exemplified by the rising intensity of regional value or supply chains - which has led businesses to push negotiators and governments to simplify the RoO that apply in PTAs.

Two of the largest trade powers, the EU and US, have made some progress towards simplification of RoO in their PTAs and preferential access programs for developing countries. There have been positive spillovers for trade integration agreements, including in the Asia-Pacific region (e.g., the TPP). The issue at stake for the global trading system is how to leverage these various positive developments 
and to cross fertilize (multilateralize) the simplifications and partial convergence in $\mathrm{RoO}$ that is reflected in recent PTAs. One path to do so is to break the wall that has separated preferential and nonpreferential RoO. In a number of sectors (e.g., chemicals) bridges spanning the preferential and nonpreferential $\mathrm{RoO}$ divide have already been built.

Discussions in the WTO CRO aimed at greater harmonization and simplification of nonpreferential $\mathrm{RoO}$ have not been successful in generating an agreement to apply a set of common RoO. This should not preclude countries interested in pursuing these objectives from doing so in a concerted fashion through a plurilateral initiative on RoO. The WTO provides a framework for members to do so, and such initiatives have been pursued in the past to liberalize trade in specific types of goods or to agree on specific rules of the game for services sectors. At the $11^{\text {th }}$ WTO Ministerial conference in Buenos Aires at the end of 2017 groups of countries agreed to explore the possibility of plurilateral cooperation in areas such as e-commerce, suggesting an interest and willingness to pursue cooperation on a plurilateral basis. The end result may be new CMAs.

One area that would appear to lend itself well to such plurilateral cooperation are $\mathrm{RoO}$, in part because of the nascent trends towards greater convergence in RoO observed in recent PTAs for some types of products and sectors. A necessary condition for determining where such cooperation is feasible and could be pursued is analysis of the type undertaken by Crivelli and Inama (2017). Further development and use of the taxonomies proposed in that paper to measure convergence in PRSO would help to identify where simplification and convergence has been taking place and thus where it may be possible to agree, on a plurilateral basis, that $\mathrm{RoO}$ are equivalent, thereby facilitating trade by lowering costs for international businesses and traders of the participating countries.

\section{REFERENCES}

Anliker, M. 2016. Non-Preferential Rules of Origin: High Level Assessment. Geneva: Price Waterhouse Coopers.

Bombarda, P. and E. Gamberoni. 2013. "Firm Heterogeneity, Rules of Origin and Rules of Cumulation," International Economic Review, vol. 54, no. 1, pp. 307-328.

Cadot, O. and L. Y. Ing. 2016. "How Restrictive are ASEAN's RoOs?," Asian Economic Papers, vol. 15, no. 3, pp. 115-134. 
Cadot, O., Carrere, C., de Melo, J. and B. Tumurchudur. 2006. "Product-specific Rules of Origin in EU and US Preferential Trading Arrangements: An Assessment," World Trade Review, vol. 5, no. 2, pp. 199-224.

Conconi, P., García-Santana, M., Puccio, L. and R. Venturini. 2016. From Final Goods to Inputs: The Protectionist Effect of Rules of Origin. CEPR Discussion Paper, no. 11084.

Crivelli, P. and S. Inama. 2017. Comparative Analysis of RoO in Recent FTAs. UNCTAD and EUI. Excel Workbook and Related Tables. In Progress.

Delegation of Switzerland. 2016. Principles and Guidelines to Streamline and Simplify Nonpreferential Rules of Origin. Geneva: World Trade Organization. (JOB/RO/6 and $\mathrm{JOB} / \mathrm{RO} / 7$ )

Edwards, J. 2016. Report on the Effects of Duties and Working Within a Duty Free Environment.

Estevadeordal, A. 1999. Negotiating Preferential Market Access: The Case of NAFTA. IDB Working Paper, no. 3.

Estevadeordal, A. and K. Suominen. 2006. Mapping and Measuring Rules of Origin Around the World. In Cadot, O., Estevadeordal, A., Suwa-Eisenmann, A. and T. Verdier. (eds.) The Origin of Goods: Rules of Origin in Regional Trade Agreement. Oxford: CEPR and Oxford University Press. pp. 69-113.

. 2008. What are the Trade Effects of Rules of Origin?. In Estevadeordal A. and K. Suominen. (eds.) Gatekeepers of Commerce: Rules of Origin and International Economic Integration. New York: Inter-American Development Bank.

Estevadeordal, A., Harris, J. and K. Suominen. 2009. Multilateralizing Preferential Rules of Origin Around the World. IDB Working Paper, no. IDB-WP-137.

Hoekman, B. and M. Kostecki. 2009. The Political Economy of the World Trading System. ( $3^{\text {rd }}$ ed.) Oxford: Oxford University Press.

Hoekman, B. and P. Mavroidis. 2015a. "WTO à la Carte or WTO Menu du Jour: Assessing the Case for Plurilateral Agreements," European Journal of International Law, vol. 26, no. 2, pp. 319-343.

2015b. "Embracing Diversity: Plurilateral Agreements and the Trading System," World Trade Review, vol. 14, no. 1, pp. 101-116.

2017. "MFN Clubs and Scheduling Additional Commitments in the GATT: Learning from the GATS," European Journal of International Law, vol. 28, no. 2, pp. 387-407.

Inama, S. 2009. Rules of Origin in International Trade. Cambridge: Cambridge University Press.

2011. "The Reform of the EC GSP Rules of Origin: Per aspera ad astra?," Journal of World Trade, vol. 45, no. 3, pp. 577-603.

Inama, S. and E. Sim. 2015. Rules of Origin in ASEAN: A Way Forward. Cambridge: Cambridge Univesity Press.

Inama, S., Vermulst, E. and P. Eeckhout. 2009. Nonpreferential Origin Rules in Antidumping Law and Practice. In Bagwell, K., Bermann, G. and P. Mavroidis. (eds.) Law and Economics of Contingent Protection in International Trade. Cambridge: Cambridge University Press. pp. 276-308. 
Keizer, W. 1997. "Negotiations on Harmonized Non-Preferential Rules of Origin: A Useless Task from a Trade Policy Perspective?," Journal of World Trade, vol. 31, no. 4, pp. 145151.

Lawrence, R. 2006. "Rulemaking Amidst Growing Diversity: A 'Club of Clubs' Approach to WTO Reform and New Issue Selection," Journal of International Economic Law, vol. 9, no. 4, pp. 823-835.

Mavroidis, P. C. 2016. The Regulation of International Trade. Cambridge MA: MIT Press. Soprano, R. 2016. "The Challenge of Designing "New" Rules of Origin in International Trade," EUI, Mimeo.

Swedish Board of Trade and UNCTAD. 2017. Excel Workbook and Related Tables. In Progress.

First version received on 9 January 2018

Peer-reviewed version received on 26 January 2018

Final version accepted on 2 March 2018 